\title{
Antibodies to Gliomedin Cause Peripheral Demyelinating Neuropathy and the Dismantling of the Nodes of Ranvier
}

\author{
Jérôme J. Devaux \\ From the Centre de Recherche en Neurobiologie et \\ Neurophysiologie de Marseille, National Center for Scientific \\ Research (CNRS), Aix-Marseille University, Marseille, France
}

Guillain-Barré syndrome (GBS) and chronic inflammatory demyelinating polyneuropathy (CIDP) are conditions that affect peripheral nerves. The mechanisms that underlie demyelination in these neuropathies are unknown. Recently, we demonstrated that the node of Ranvier is the primary site of the immune attack in patients with GBS and CIDP. In particular, GBS patients have antibodies against gliomedin and neurofascin, two adhesion molecules that play a crucial role in the formation of nodes of Ranvier. We demonstrate that immunity toward gliomedin, but not neurofascin, induced a progressive neuropathy in Lewis rats characterized by conduction defects and demyelination in spinal nerves. The clinical symptoms closely followed the titers of anti-gliomedin IgG and were associated with an important deposition of IgG at nodes. Furthermore, passive transfer of antigliomedin IgG induced a severe demyelinating condition and conduction loss. In both active and passive models, the immune attack at nodes occasioned the loss of the nodal clusters for gliomedin, neurofascin186 , and voltage-gated sodium channels. These results indicate that primary immune reaction against gliomedin, a peripheral nervous system adhesion molecule, can be responsible for the initiation or progression of the demyelinating form of GBS. Furthermore, these autoantibodies affect saltatory propagation by dismantling nodal organization and sodium channel clusters. Antibodies reactive against nodal adhesion molecules thus likely participate in the pathologic process of GBS and CIDP. (Am J Pathol 2012, 181:14021413; bttp://dx.doi.org/10.1016/j.ajpath.2012.06.034)

Guillain-Barré syndrome (GBS) is a group of inflammatory neuropathies that affect peripheral nerves. In Europe, acute inflammatory demyelinating polyneuropathy (AIDP) is the most common form of GBS. Autopsy and biopsy studies indicated that both humoral and cellular immune reaction against Schwann cell or axonal antigens are implicated in GBS etiology. ${ }^{1}$ Early investigations have found that conduction defects closely correlate with myelin retraction and macrophage invasion in many patients. ${ }^{2-5}$ Some GBS cases also involve acute demyelination without immune cell invasion and are primarily humorally mediated. ${ }^{6,7}$ In particular, deposition of complement on the abaxonal surface of the Schwann cells has been shown during the early stage of $\mathrm{GBS}^{8-10}$ and in experimental allergic neuritis (EAN). ${ }^{11}$ In a recent study, we demonstrated that nodes of Ranvier and paranodes are the targets of the immune attack in GBS and in chronic inflammatory demyelinating polyneuropathy (CIDP). ${ }^{12}$ Notably, cell adhesion molecules (CAMs) at nodes or paranodes (gliomedin, neurofascin, and contactin) were recognized by IgG antibodies in patients with GBS or CIDP. ${ }^{12,13}$ Autoantibodies against neurofascin and gliomedin were also detected in a rat model of AIDP and correlated with important conduction defects. ${ }^{14}$ This finding suggested that antibodies to nodal CAMs may participate to the pathogenesis of AIDP and CIDP. However, the exact mechanisms by which these humoral factors mediate demyelination and conduction defects are still elusive.

Several CAMs are implicated in node formation and are responsible for the enrichment of voltage-gated sodium

Supported by the French Muscular Dystrophy Association (AFM) (MNM1 2010-14580), the GBS/CIDP Foundation International, and the National Center for Scientific Research (CNRS).

Accepted for publication June 20, 2012.

The monoclonal antibodies against Nav1.6 were obtained from the University of California, Davis, National Institute of Neurological Disorders and Stroke, National Institute of Mental Health, NeuroMab Facility, supported by NIH grant U24NS050606, and maintained by the Department of Pharmacology, School of Medicine, University of California, Davis.

Address reprint requests to Jérôme J. Devaux, Ph.D., Centre de Recherche en Neurobiologie et Neurophysiologie de Marseille - CRN2M UMR 7286, CNRS, Aix-Marseille Univ, Faculté de Médecine - Secteur Nord, CS80011, Bd Pierre Dramard, 13344 Marseille Cedex 15, France. E-mail: jerome.devaux@univ-amu.fr. 
(Nav) channels at the nodes of Ranvier. ${ }^{15}$ At peripheral, nodes gliomedin and NrCAM are secreted into the nodal gap lumen and interact with neurofascin-186 (NF186) expressed at nodal axolemma. ${ }^{16-19}$ This interaction is crucial for Nav channel aggregation at nodes. ${ }^{19-21}$ In addition, the paranodal axoglial junctions are made by the association of contactin and contactin-associated protein (Caspr) with neurofascin-155 (NF155), a variant expressed in glia. ${ }^{22}$ This adhesive junction forms a barrier to the lateral diffusion of nodal channels. ${ }^{19,21,23}$ In a rat model of AIDP, we found that the loss of NF186 and gliomedin at nodes preceded paranodal demyelination and the diffusion of Nav channels in demyelinated segments. ${ }^{14}$ This finding indicated that antibodies to nodal CAMs may participate to conduction defects by dismantling axoglial attachment at nodes and paranodes.

We investigated whether immunity toward gliomedin and NF186 can trigger peripheral neuropathies and be responsible for demyelination in GBS patients. We found that im- munization against gliomedin induced a biphasic condition associated with conduction loss and demyelination. Passive transfer of antibodies to gliomedin exacerbated the clinical signs of EAN and resulted in the disorganization of the nodes of Ranvier. Altogether, these results demonstrate that humoral immune response directed against nodal CAMs participates in conduction abnormalities in peripheral nerves and in the etiology of GBS and CIDP.

\section{Materials and Methods}

\section{Immunization}

The extracellular domain of NF186 fused to human IgG $F_{C}\left(N F 186-F_{C}\right)$ and gliomedin fused to human IgG FC (Gldn-Fc) were obtained as described previously 22,24 and stored at $-80^{\circ} \mathrm{C}$. The human IgG Fc fragment was purchased from Bethyl Laboratories (Montgomery, TX).
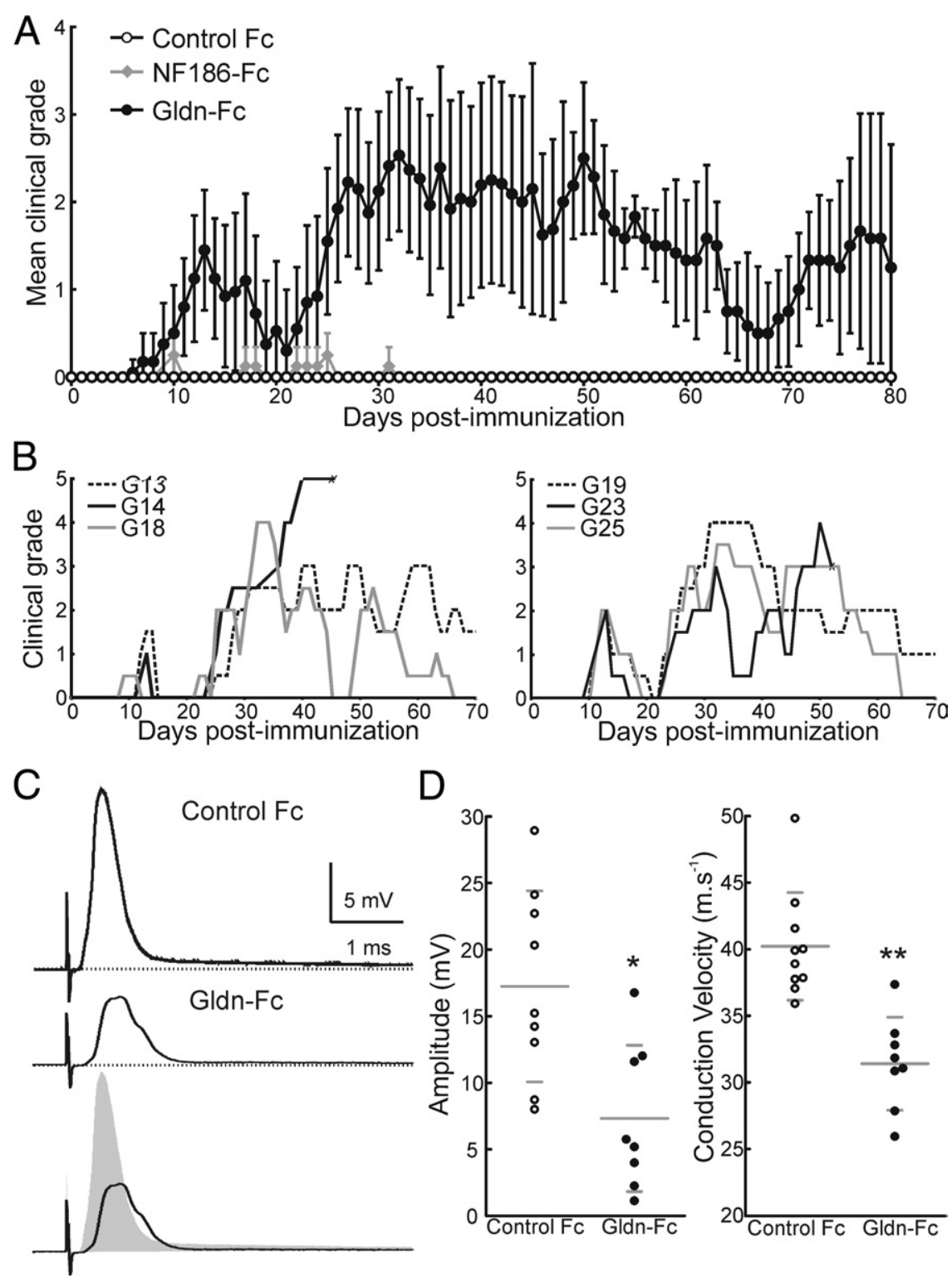

D
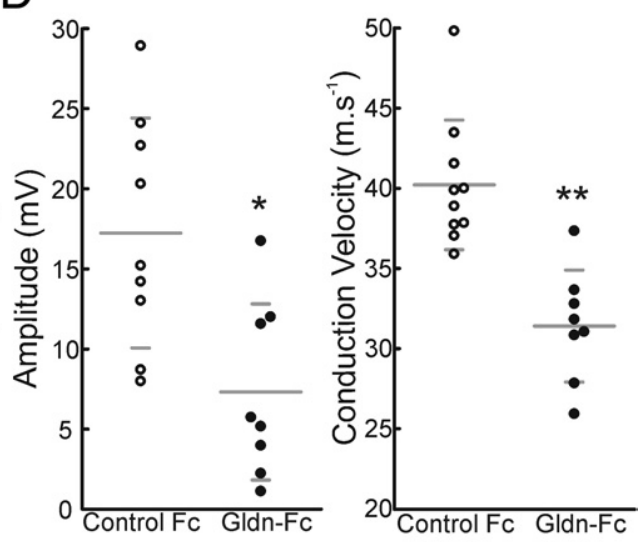

Figure 1. Animals immunized against gliomedin develop neurological signs. A: Lewis rats were immunized against Gldn-Fc $(n=20)$, NF186-Fc $(n=8)$, or human IgG Fc (Control Fc; $n=10$ ), and the clinical scores were monitored daily and averaged. Gliomedin-sensitized animals developed two episodes of clinical symptoms that completely remitted by 90 days after immunization. By contrast, animals sensitized against NF186-FC or human IgG FC did not show significant clinical signs. B: Individual clinical grades from six representative gliomedin-sensitized animals reveal that the disease course was variable among individuals. In some animals, the clinical signs plateaued for up to 7 weeks (G13 and G19). Other animals showed fluctuating clinical signs (G18, G23, and G25). C: Nerve activity was recorded in L6 ventral spinal roots from control ( $n=8$ nerves from 4 animals; upper trace) and gliomedin-sensitized animals ( $n=10$ nerve from 6 animals; middle trace) at disease peaks (between 30 and 45 days after immunization). D: Gliomedin-sensitized animals had a significant decrease in CAP amplitude and conduction velocity compared with controls. ${ }^{*} P<0.01,{ }^{* *} P<0.001$ by unpaired two-tailed Student's $t$-tests for two samples of equal variance. Horizontal lines indicate the mean and SD. 
Male inbred adult Lewis rats (6 to 7 weeks old; Elevage Janvier, Le Genest St Isle, France) were sensitized by subcutaneous injection at the base of the tail with $200 \mu \mathrm{L}$ of an antigen emulsion. The antigens were emulsified with an equal volume of complete Freund's adjuvant (SigmaAldrich, St. Louis, MO). Final doses in the inoculum were $100 \mu \mathrm{g}$ of H37RA Mycobacterium tuberculosis and $50 \mu \mathrm{g}$ of $\mathrm{Fc}$ fusion proteins. Animals received intraperitoneal injections of $200 \mathrm{ng}$ of pertussis toxin in PBS on the day of immunization and 48 hours after immunization. Animals were weighed and observed daily. Clinical signs were graded as follows: 0, no illness; 1 , tail tip hanging; 2, limp tail; 3, tail paralysis; 4, gait ataxia; 5, mild paraparesis; 6, severe paraparesis; 7, paraplegia; 8 , tetraparesis; 9, moribund; and 10, death. All of the experiments were in lines with the European Community's guiding principles on the care and use of animals (86/609/CEE).

\section{IgG Purification and Passive Transfer}

Blood was collected by cardiac puncture at disease peaks (30 days after immunization) from six animals immunized with Gldn-Fc or control Fc. IgG was purified from serum samples by affinity chromatography with protein $\mathrm{G}$ sepharose according to the manufacturer protocol (Sigma-Aldrich). The synthetic peptide of bovine P2 myelin protein (amino acids 53 to 78$)^{25}$ was purchased from Bachem (Bubendorf, Switzerland) and dissolved in saline $(2 \mathrm{mg} / \mathrm{mL})$. Lewis rats were sensitized with 50 $\mu \mathrm{g}$ of P2 antigen (EAN-P2) in $100 \mu \mathrm{L}$ of saline emulsified with $100 \mu \mathrm{L}$ of complete Freund's adjuvant. At the onset of disease (12 days after immunization), rats received i.p. injections of $500 \mu \mathrm{g}$ of purified antigliomedin IgG or control rat IgG. In parallel, naive Lewis rats received i.p. injections of $500 \mu \mathrm{g}$ of purified anti-gliomedin IgG. Animals were weighed and examined daily for clinical signs.

\section{Immunolabeling and Histopathologic Analysis}

L6 spinal nerves from immunized Lewis rats and sciatic nerves from adult C57BL/6J mice were dissected and fixed in $2 \%$ paraformaldehyde in PBS for 1 hour at $4^{\circ} \mathrm{C}$, then rinsed in PBS. Axons were gently teased, dried on glass slides, and stored at $-20^{\circ} \mathrm{C}$. In some experiments, unfixed L6 spinal roots were rapidly teased, dried, and frozen. Alternatively, fixed spinal nerves were cryoprotected in $30 \%$ sucrose in $0.1 \mathrm{~mol} / \mathrm{L}$ PBS overnight at $4^{\circ} \mathrm{C}$, then cut into 5- to 10- $\mu \mathrm{m}$-thick cryosections. Frozen sections and teased fibers were permeabilized by immersion in $-20^{\circ} \mathrm{C}$ acetone for 10 minutes, blocked at room temperature for 1 hour with $5 \%$ fish skin gelatin containing $0.1 \%$ Triton X-100 in PBS, and incubated overnight at $4^{\circ} \mathrm{C}$ with various combinations of primary antibodies or sera: rabbit anti-sera against gliomedin (1/500), ${ }^{24} \mathrm{NF} 186(1 /$ $500),{ }^{26}$ or Caspr (1/1000) ${ }^{27}$; mouse monoclonal antibodies against PanNav channels (K58/35; 1:500; Sigma-Aldrich), Nav1.6 (1/100; University of California, Davis, National Institute of Neurological Disorders and Stroke, National Institute of Mental Health, NeuroMab Facility, Davis, CA), ED1 (1/200; AbD Serotec, Oxford, UK), CD3
(1/200; AbD Serotec), or C5b-9 (1/50; DakoCytomation, Glostrup, Denmark); goat antibody against contactin (1/ 200; R\&D Systems, Minneapolis, MM) or rat complement C3 (Nordic Immunological Laboratories, Tilburg, The Netherlands); or rat sera diluted $1 / 200$ to $1 / 2000$. The slides were then washed several times and incubated with the appropriate Alexa-conjugated secondary antibodies (1/500; Invitrogen, Paisley, UK). Slides were mounted with Mowiol plus $2 \%$ 1,4-diazabicyclo[2.2.2]octane and examined using an ApoTome fluorescence microscope (ApoTome, AxioObserver and AxioCam MRm, Carl Zeiss Microlmaging $\mathrm{GmbH}$, Jena, Germany). Digital images were manipulated into figures with Adobe Photoshop (Adobe Systems Inc, San Jose, CA) and CorelDraw (Corel Corporation, Ottawa, ON, Canada). Teased fibers from five animals were analyzed for each group ( 500 axons counted in total). The lengths of individual Caspr-positive paranodes and intercalated nodes were measured using ImageJ software version 1.43u ( $\mathrm{NIH}$, Bethesda, MD). For the quantification of demyelinated axons, teased fibers were stained for Caspr, and intercalated nodes larger than 5 $\mu \mathrm{m}$ were counted as demyelinated. For histopathologic analysis, L6 spinal nerves were fixed in $2 \%$ paraformaldehyde and $2 \%$ glutaraldehyde in $0.1 \mathrm{~mol} / \mathrm{L}$ PBS overnight at $4^{\circ} \mathrm{C}$ and postfixed in $1 \% \mathrm{OsO}_{4}$ in $0.1 \mathrm{~mol} / \mathrm{L} \mathrm{PBS}$ for 1 hour. Nerves were dehydrated and embedded in epoxy resin. Transverse semithin sections were stained with toluidine blue and examined by light microscopy. The number of degenerated myelinated axons was measured in five animals for each group (all of the fibers in the roots were counted; $\sim 1000$ axons per animals). Schwann tubes, $>2 \mu \mathrm{m}$ in diameter and typically containing myelin debris but no recognizable axon, were considered to be degenerating myelinated axons.

\section{Cell-Binding Assay}

Blood was collected from the lateral tail vein before immunization (preimmune), and at 7, 14, 21, 30, 45, and 80 days after immunization. Blood was allowed to clot for 30

Table 1. Characteristics of CAPs from Ventral Spinal Roots of Animals Immunized Against Gliomedin

\begin{tabular}{lcc}
\hline & \multicolumn{2}{c}{ Lewis rats immunized against } \\
\cline { 2 - 3 } \multicolumn{1}{c}{ Characteristic } & FC & Gldn-FC \\
\hline Amplitude $(\mathrm{mV})$ & $17.2 \pm 6.8$ & $7.3 \pm 5.1^{*}$ \\
Area $(\mathrm{mV} \cdot \mathrm{ms})$ & $4041 \pm 2014$ & $2247 \pm 1395^{\star}$ \\
Duration $(\mathrm{ms})$ & $0.43 \pm 0.09$ & $0.54 \pm 0.27$ \\
$\mathrm{CV}_{\mathrm{V}^{1 / 2}}\left(\mathrm{~m} \cdot \mathrm{s}^{-1}\right)$ & $40.2 \pm 3.8$ & $31.8 \pm 3.5^{*}$ \\
$\mathrm{CV}_{\mathrm{Vmax}_{\text {max }}\left(\mathrm{m} \cdot \mathrm{s}^{-1}\right)}$ & $27.5 \pm 3.3$ & $21.7 \pm 4.5^{*}$ \\
No. & $8(4)$ & $10(6)$ \\
Days of analysis after & 30 & $30-45$ \\
immunization & & \\
\hline
\end{tabular}

The data were recorded at the peaks of severity from L6 ventral roots of animals immunized against human Fc or Gldn-Fc. Data are presented as mean $\pm \mathrm{SD}$.

*Significantly different $P<0.01$ with two-tailed $t$-tests for two samples of equal variance.

†No. represents the number of nerves tested. The number of animals tested is indicated in parentheses.

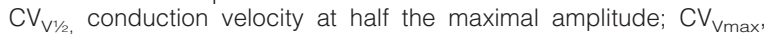
conduction velocity at peak amplitude. 
minutes at room temperature, then blood was centrifuged for 10 minutes at $3000 \times g$, and serum samples were collected. Human embryonic kidney (HEK) cells were transiently transfected with rat NF186 (NM_001160314.1; HA tagged) or rat gliomedin (NM_181382.2; Myc tagged) using JetPEI (Polyplus-transfection, Illkirch, France). One day after transfection, cells were trypsinated, suspended in serum free Opti-MEM medium (Invitrogen), and plated onto poly-L-lysine coated glass coverslips in 24-well plates at a density of 100,000 cells per well. One day after, living cells were incubated for 20 minutes with 50 $\mu \mathrm{L}$ of serum diluted at $1 / 50$ to $1 / 10,000$ in blocking solution (5\% fish skin gelatin in PBS). Serum samples were preincubated for 30 minutes at room temperature with fluorescein isothiocyanate-conjugated anti-rat IgM (1/50) or tetramethyl rhodamine isothiocyanate-conjugated anti-rat IgG (1/50). Cells were washed three times in PBS, fixed with $2 \%$ paraformaldehyde in $0.1 \mathrm{~mol} / \mathrm{L}$ PBS for 20 minutes, rinsed in PBS, and blocked for 30 minutes. Cells were then incubated for 1 hour with primary antibodies: rat monoclonal antibodies against HA (1/200; Roche, Basel, Switzerland) or mouse monoclonal antibodies against Myc (1/500; Roche). The cells were then washed and revealed with the appropriate Alexa-conjugated secondary antibodies (1/500; Invitrogen). Cells were stained with DAPI and mounted with Mowiol plus 2\% 1,4-diazabicyclo[2.2.2]octane.

\section{Electrophysiology}

Recordings were performed at different stages of the disease. After euthanizing, the caudal equine were quickly dissected and transferred into artificial cerebrospinal fluid equilibrated with $95 \% \mathrm{O}_{2}-5 \% \mathrm{CO}_{2}$, which
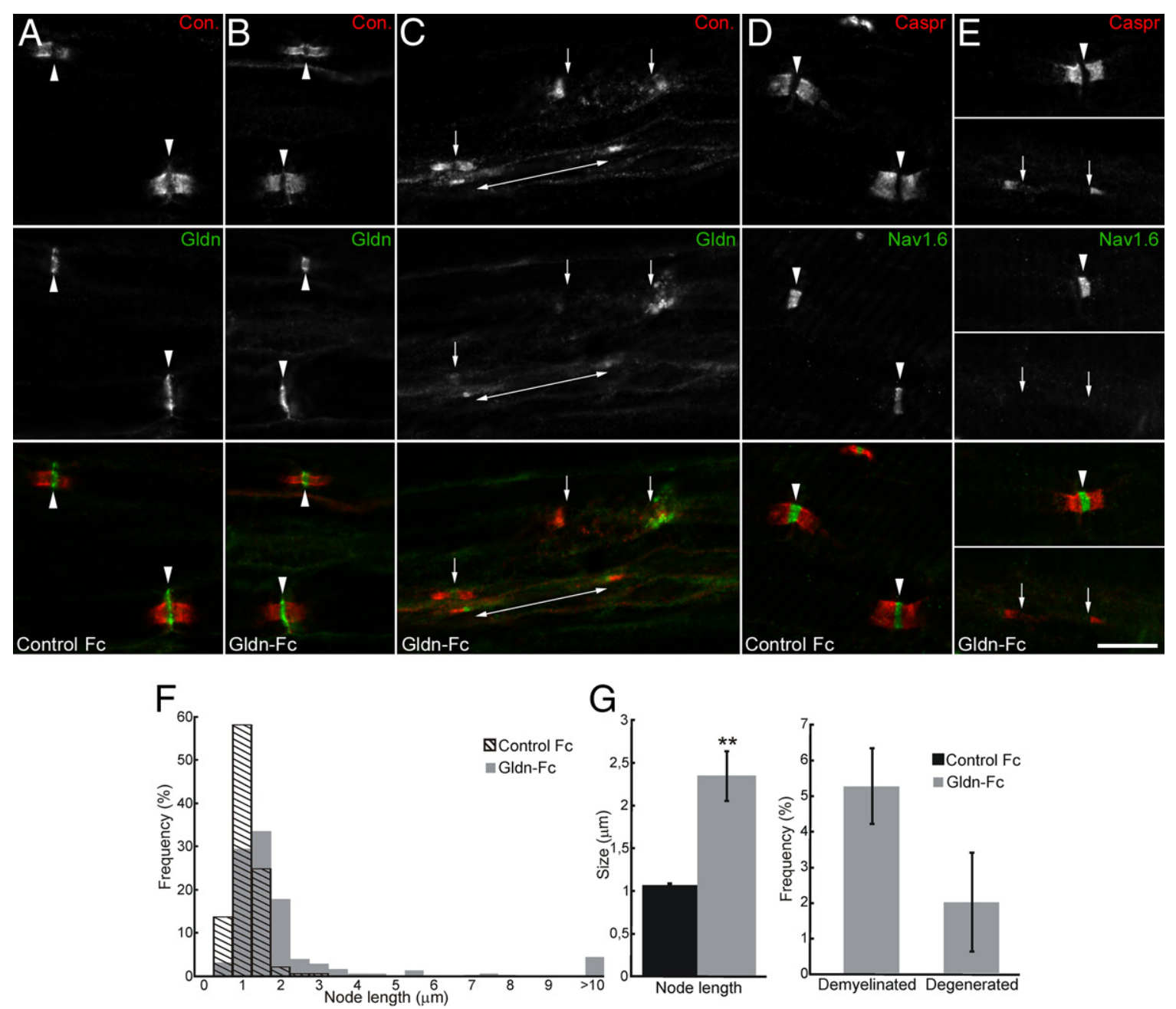

Figure 2. Nodal clusters are disrupted in gliomedin-sensitized animals. A-E: Teased fibers from L6 ventral roots from control and gliomedin-sensitized animals at disease peaks stained for contactin (red) and gliomedin (green; A-C) or Nav channels (green, D and E). In control animals, Nav channels and gliomedin are concentrated at high densities at the nodes of Ranvier (arrowheads) and are flanked by contactin-positive paranodes (A and $\mathbf{D}$ ). In gliomedin-sensitized animals (B, C, and E), Nav channels and gliomedin were concentrated at most nodes of Ranvier and were clustered at heminodes in demyelinated segments (double-ended arrows). In some nodes and demyelinated axons ( $\mathbf{C}$ and $\mathbf{E}$, bottom panels), clusters of gliomedin and Nav channels were disrupted (arrows). Scale bars: $10 \mu \mathrm{m}$. F and G: L6 ventral spinal roots from control ( $n=8$ animals; 596 axons) and gliomedin-sensitized animals $(n=9$ animals; 841 axons) were stained for Caspr, and the length of the intercalated nodes was measured. Axons with node widening superior to $5 \mu \mathrm{m}$ were considered demyelinated. Axonal degeneration was measured from transverse sections of L6 ventral spinal roots. Node length was significantly increased in gliomedin-sensitized animals. *** $P<$ 0.001 by unpaired two-tailed Student's $t$-tests and Kolmogorov-Smirnov test. In addition, gliomedin-sensitized animals presented signs of paranodal demyelination and few degenerated axons. 
contained $126 \mathrm{mmol} / \mathrm{L} \mathrm{NaCl}, 3 \mathrm{mmol} / \mathrm{L} \mathrm{KCl}, 2 \mathrm{mmol} / \mathrm{L}$ $\mathrm{CaCl}_{2}, 2 \mathrm{mmol} / \mathrm{L} \mathrm{MgSO}{ }_{4}, 1.25 \mathrm{mmol} / \mathrm{L} \mathrm{NaH} \mathrm{NO}_{4}, 26$ $\mathrm{mmol} / \mathrm{L} \mathrm{NaHCO}_{3}$, and $10 \mathrm{mmol} / \mathrm{L}$ dextrose, $\mathrm{pH} 7.4$ to 7.5 . The L6 ventral spinal roots were cut into 2-cm segments, and recordings of nerve compound action potentials (CAPs) were made at $36^{\circ} \mathrm{C}$ in a three-compartment recording chamber as previously described. ${ }^{14}$ Nerves were stimulated at a single site. The delay and duration of the CAPs were calculated at half the maximal amplitude. Conduction velocities were estimated from latencies. For recruitment analysis, nerves were stimulated at increasing intensities. For refractory period analysis, two stimuli were applied at different intervals, and the amplitude of the second CAP was measured and plotted as a function of the stimulus interval.

\section{Results}

\section{Induction of EAN by Immunization Against Gliomedin}

To determine whether the immune reaction toward nodal proteins participates in the pathogenesis of AIDP, Lewis rats were immunized with the extracellular domains of NF186-Fc; $50 \mu \mathrm{g})$ and Gldn-Fc $(50 \mu \mathrm{g})$. Animals were treated with pertussis toxin on days 0 and 2 to potentiate the immune response. NF186-FC or Fc alone did not induce significant neurologic signs in Lewis rats. By contrast, animals immunized against Gldn-Fc developed progressive neurologic symptoms within 7 to 9 days (Figure $1 \mathrm{~A}$ ). The clinical course was biphasic, with a first peak at days 12 to 15 followed by a complete remission and a clinical worsening starting around 21 days after immunization (Figure 1, A and B). The course of the secondary phase was variable among individuals and lasted for several weeks. Some animals presented a relapse-remitting course, whereas other presented a secondary progressive rise to a plateau (Figure 1B). At disease peaks, animals exhibited a maximal clinical score of approximately 4 (see Supplemental Figure S1C at $h t t p: / /$ ajp.amjpathol.org) characterized by tail paralysis and gait abnormalities. Higher doses of immunogen did not enhance clinical signs or reveal symptoms in the case of NF186-FC.

Electrophysiologic examinations at disease peaks (between 30 and 45 days after immunization) demonstrated that gliomedin-sensitized animals exhibited important conduction deficits in L6 ventral spinal nerves with a marked decrease in CAP amplitude and in conduction velocity (Figure 1 and Table 1). These alterations were associated with a significant increase in the refractory period and a displacement of the recruitment curve toward higher voltages $(P<0.01$; see Supplemental Figure S1A at http://ajp.amjpathol.org), which are hallmarks of demyelinating conditions. However, sciatic nerves, L5 ventral spinal roots, or dorsal roots were less affected (data not shown). Altogether, these results indicated that immunity to gliomedin induces a predominantly motor demyelinating neuropathy.

\section{Immunity Against Gliomedin Induces Demyelination and Node Disruption}

To examine the organization of the nodes of Ranvier, L6 ventral spinal roots were immunostained for Caspr or contactin. Caspr and contactin showed the expected distinct paranodal distribution (Figure 2). However, many axons showed signs of nodal elongation or paranodal demyelination (Figure 2, C and E). The length of unstained nodal gap was determined from nine different animals and was found to be significantly widened in gliomedin-sensitized animals (Figure 2, F and G). More than $5 \%$ of the nodes were $>5 \mu \mathrm{m}$ in length and were undergoing paranodal demyelination. No signs of demyelination were observed in animals immunized against NF186-Fc or control Fc.

Next, I investigated the possibility that nodal organization was affected in gliomedin-sensitized animals. In most axons, NF186, gliomedin, and Nav channels were properly clustered at normal-appearing nodes (Figure 2 and Table 2). However, NF186, gliomedin, and Nav channels were missing or diffusely localized in most demyelinated segments (Figure 2E and Table 2). Only a few demyelinated segments showed NF186, gliomedin, or Nav channel clusters at heminodes that flanked the paranodes (Figure 2C). These results indicated that node elongation, demyelination, and node disruption might account for conduction defects and neurologic signs in these animals.

\section{The Node of Ranvier Is the Locus of the Immune Attack}

To understand the immunopathologic mechanisms underlying EAN, spinal nerves were examined for immune cell infiltration or IgG deposits at disease peaks (30 to 45 days after immunization). Semithin transverse sections confirmed the presence of demyelination. Only a few degenerated axons were visible at disease peaks and

Table 2. Percentage of Nodal Cluster Disruption in Animals Immunized Against Gliomedin

\begin{tabular}{lcc}
\hline & Fc & Gldn-Fc \\
\hline Rabbit $\alpha$-gliomedin & & \\
Normal nodes (\%) & 99.1 & 92.2 \\
Disrupted nodes (\%) & 0.9 & 7.8 \\
No. & 802 & 805 \\
Rabbit $\alpha$-NF186 & 99.2 & 90.8 \\
$\quad$ Normal nodes (\%) & 0.8 & 9.2 \\
Disrupted nodes (\%) & 602 & 692 \\
No. & 99.2 & 96.1 \\
Mouse $\alpha$-PanNav & 0.8 & 3.9 \\
Normal nodes (\%) & 1054 & 1144 \\
Disrupted nodes (\%) & 30 & $30-45$ \\
$\quad$ No. & \\
Days of analysis after immunization & 30 \\
\hline
\end{tabular}

Teased fibers were prepared at the peaks of severity from L6 ventra roots of five different animals immunized against human Fc or Gldn-Fc. The teased fibers were stained with the indicated antibodies and a goat antiserum anti-contactin. Nodes and heminodes with bright and focal gliomedin, NF186, or PanNav staining were considered normal nodes. Nodes and heminodes with diffuse and weak staining were considered disrupted. No. represents the number of nodes examined. 
may be secondary to demyelination or inflammation (Figure $2 \mathrm{G}$ ). Worth noting, spinal nerves appeared devoid of immune cell infiltration.

Consistently, no signs of CD3-positive $T$ cells were found in spinal nerves (data not shown), and only a few ED1-positive macrophages were detected in gliomedinsensitized animals (see Supplemental Figure S2 at http:// ajp.amjpathol.org). Instead, a strong IgG deposit was de- tected at most nodes (57\%; $n=4$ animals) in L6 ventral spinal nerves (Figure 3, F and G). This finding was associated with a faint deposition of the terminal complement complex (C5b-9) in 22\% of the nodes ( $n=4$ animals; Figure 3, $\mathrm{H}$ and I). Worth noting, IgG deposits were mostly found at intact nodes but were not detected in demyelinated axons. No IgG or complement deposition was found in control animals (Figure 3). Also, no IgM
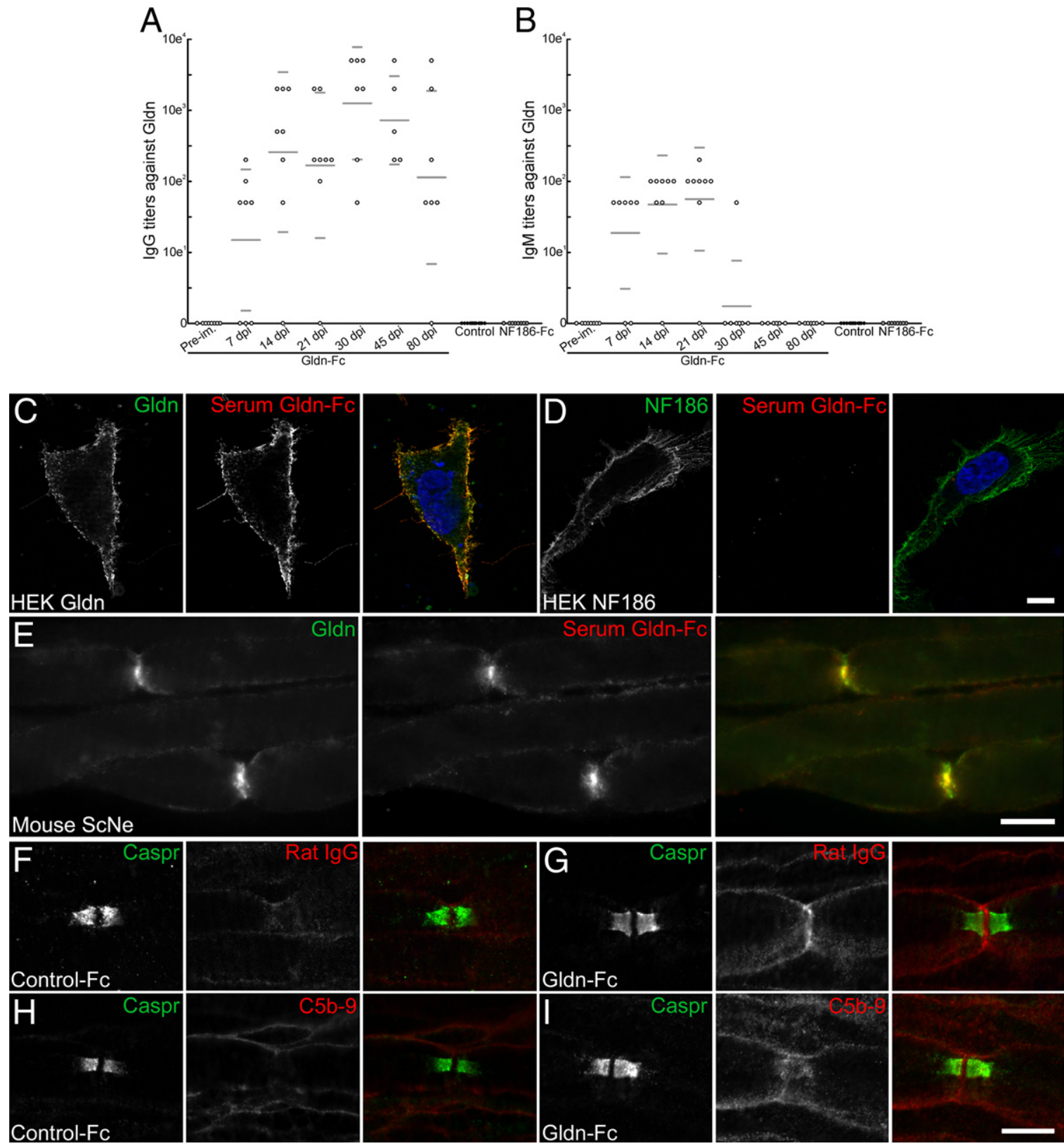

Figure 3. Gliomedin-sensitized animals showed a rapid IgG response against gliomedin and IgG deposits at nodes. A and B: Serum samples were collected from gliomedin-sensitized animals before immunization (pre-im.) and at $7(n=8), 14(n=8), 21(n=8), 30(n=7), 45(n=5)$, and $80(n=7)$ days after immunization but also from animals sensitized with human IgG Fc (control) and NF186-Fc. IgG (A) and IgM (B) titers against gliomedin were measured on living HEK cells transiently transfected with gliomedin. Horizontal lines indicate the mean and SD. As soon as 7 days after immunization, gliomedin-sensitized animals showed an important IgG response against gliomedin that lasted for several weeks and progressively decreased as the animals remitted. Animals also exhibit a transient IgM response against gliomedin. Control and NF186-sensitized animals did not show antibody response against gliomedin. C and D: IgG from gliomedin-sensitized animals specifically bound to the surface of HEK cells transfected with gliomedin (C) but did not bind the surface of NF186-transfected cells (D). E: Serum IgG from gliomedin-sensitized animals co-localized with gliomedin at nodes of Ranvier in teased fibers from mouse sciatic nerve. F-I: These are teased fibers from L6 ventral roots of control $(\mathbf{F}$ and $\mathbf{H})$ and gliomedin-sensitized animals ( $\mathbf{G}$ and $\mathbf{I})$ labeled for Caspr (green) and $\operatorname{rat} \operatorname{IgG}(\mathbf{F}$ and $\mathbf{G})$ or C5b-9 (H and $\mathbf{I})$. Note that an important IgG deposit was detected at nodes in gliomedin-sensitized animals but not in control animals. A faint deposition of C5b-9 was also found in gliomedin-sensitized animals. Scale bar $=10 \mu \mathrm{m}$ 
deposits were detected in immunized animals. These results pointed out that antigens at nodes are the targets of the immune response in these animals and suggested that the blood-nerve barrier is permeabilized.

Cell-binding assay then demonstrated that gliomedinsensitized animals developed anti-gliomedin antibodies (Figure $3 \mathrm{C}$ ). The titers of the anti-gliomedin antibodies were examined at different stages of the clinical course. An important IgG response was observed as early as 7 days after immunization when the first clinical symptoms appear (Figure 3). The mean IgG titer then closely followed the course of the disease with a first IgG peak at 14 days after immunization and a secondary IgG response at 30 days after immunization that progressively decreased as the animals remitted. Animals also presented a transient IgM response against gliomedin that started as early as 7 days after immunization and was completely vanished by 30 days after immunization. No animals immunized against control Fc or NF186 developed antibodies against gliomedin (Figure 3, A and B). Conversely, gliomedin-sensitized animals did not show IgG or IgM response against NF186 (Figure 3D; see also Supplemental Figure S1D at http://ajp.amjpathol.org). Also, NF186-sensitized animals produced antibodies against
NF186 (see Supplemental Figure S1D at http://ajp. amjpathol.org); albeit, they did not develop any peripheral neuropathy. Incubation of mouse sciatic nerve fibers with sera from gliomedin-sensitized animals (30 days after immunization) revealed that serum IgG binds the nodes of Ranvier and colocalizes with gliomedin (Figure 3). Sera from control animals did not stain the nodes of Ranvier. Altogether, these results emphasized that anti-gliomedin IgG may be responsible for IgG binding at nodes and for node alterations.

\section{Pathogenicity of Anti-gliomedin Antibodies in Vivo}

To understand whether anti-gliomedin IgG are responsible for EAN, serum IgG was purified from animals sensitized with gliomedin (sacrificed at 30 days after immunization) and were injected into naive Lewis rats. Of 10 animals injected with anti-gliomedin IgG, only two animals developed significant clinical signs, which started 3 days after injection and lasted for 14 and 34 days, respectively (see Supplemental Figure S1E at $h$ ttp://ajp. amjpathol.org). The clinical signs of these animals were

A

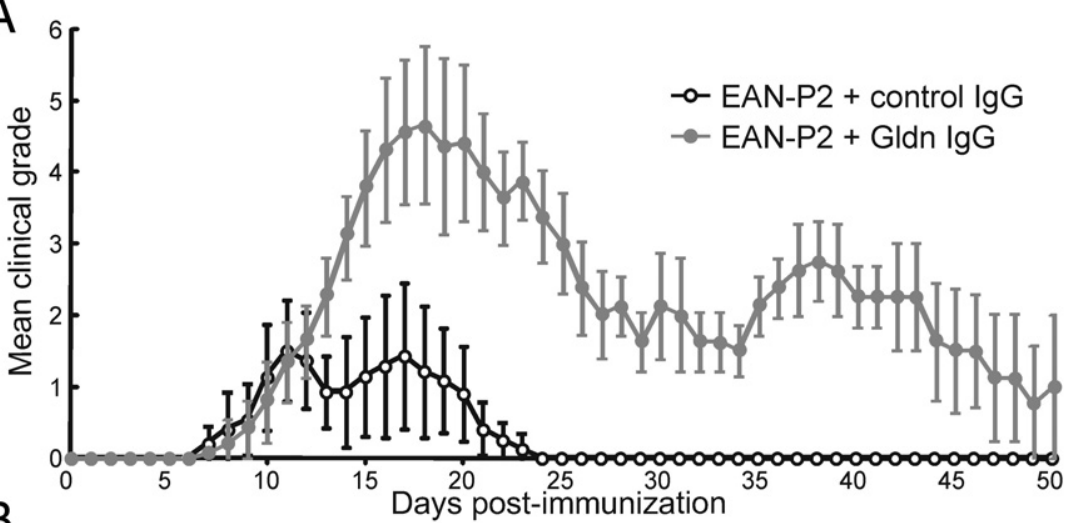

B

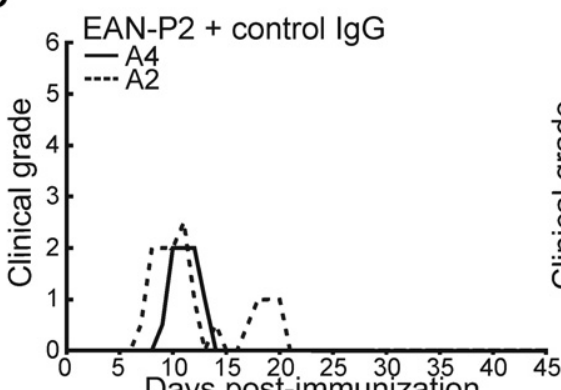

C

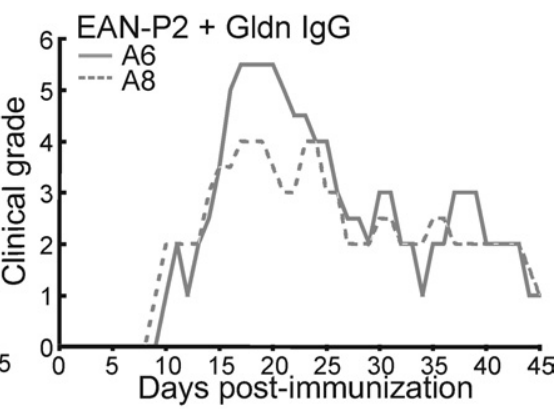

EAN-P2 + control IgG

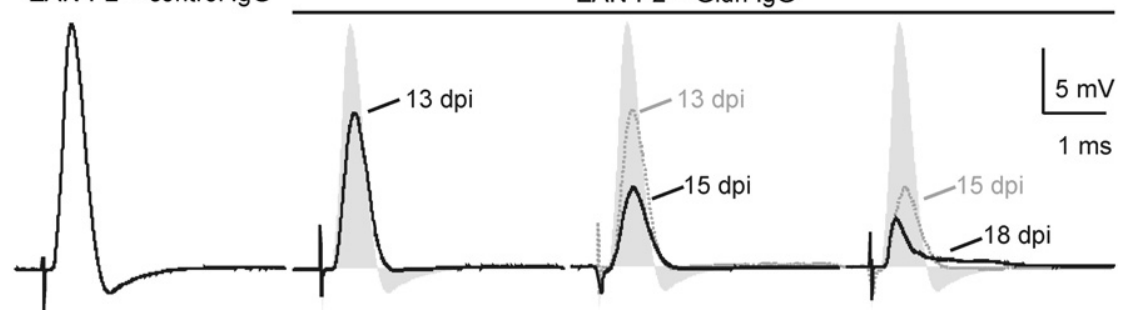

Figure 4. Passive transfer of anti-gliomedin $\operatorname{IgG}$ exacerbates the clinical signs of EAN. A: Lewis rats were immunized with low doses of P2 peptide and received anti-gliomedin $\operatorname{IgG}(n=20)$ or control IgG $(n=10)$ on day 12 . The clinical score was monitored daily and averaged. EAN-P2 animals developed faint neurologic signs that peaked at 12 days after immunization and remitted completely by 24 days. Administration of anti-gliomedin IgG exacerbated significantly the intensity and the duration of the clinical symptoms. B: Individual clinical grades from two animals administrated with control IgG (left panel) or anti-gliomedin IgG (right panel). C: L6 ventral spinal roots were recorded from EAN-P2 animals administrated with control $(n=$ 6 nerves from 5 animals) or anti-gliomedin IgG ( $n=16$ nerves from 13 animals) at 13 days after immunization, 15 days after immunization, and at disease peaks (17 to 18 days after immunization). Note that the passive transfer of anti-gliomedin IgG induced important conduction loss as early as 24 hours after the transfer of anti-gliomedin IgG (13 days after immunization). Conduction loss then progressively increased as the clinical signs worsened. At disease peaks, some nerves also exhibited signs of temporal dispersion as depicted here (right end panel). 
Table 3. Passive Transfer of Anti-Gliomedin IgG Induces Conduction Loss

\begin{tabular}{|c|c|c|c|c|}
\hline \multirow[b]{3}{*}{ Amplitude (mV) } & \multicolumn{4}{|c|}{ EAN-P2 animals administered with } \\
\hline & \multicolumn{2}{|c|}{ Control lgG } & \multicolumn{2}{|c|}{ Anti-Gliomedin IgG } \\
\hline & $20.3 \pm 7.2$ & $12.8 \pm 3.0$ & $8.1 \pm 4.8^{*}$ & $6.3 \pm 2.0^{*}$ \\
\hline Area $(\mathrm{mV} \cdot \mathrm{ms})$ & $4168 \pm 1338$ & $2567 \pm 934$ & $1728 \pm 745^{\star}$ & $1344 \pm 350^{*}$ \\
\hline Duration (ms) & $0.35 \pm 0.02$ & $0.50 \pm 0.24$ & $0.41 \pm 0.11$ & $0.3 \pm 0.02$ \\
\hline $\mathrm{CV}_{\mathrm{V}^{1 / 2} / 2}\left(\mathrm{~m} \cdot \mathrm{s}^{-1}\right)$ & $47.1 \pm 7.2$ & $38.9 \pm 8.7$ & $37.5 \pm 6.1$ & $44.6 \pm 5.0$ \\
\hline $\mathrm{CV}_{V_{\max }}\left(\mathrm{m} \cdot \mathrm{s}^{-1}\right)$ & $33.5 \pm 4.4$ & $27.4 \pm 8.0$ & $25.8 \pm 4.6^{*}$ & $32.2 \pm 3.8$ \\
\hline $\mathrm{No}^{+}$ & $6(5)$ & $5(4)$ & $6(4)$ & $5(5)$ \\
\hline Days of analysis after immunization & $15-18$ & 13 & 15 & $17-18$ \\
\hline
\end{tabular}

The data were recorded at $13,15,17$, and 18 days after immunization from L6 ventral roots of EAN-P2 animals that received control IgG or anti-gliomedin IgG. Data are presented as mean \pm SD.

*Significantly different $P<0.01$ with two-tailed $t$-tests for two samples of equal variance.

${ }^{\dagger}$ No. represents the number of nerves tested. The number of animals tested is indicated in parentheses.

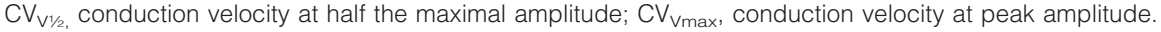

reminiscent of those found in actively immunized animals and were characterized by a tail paralysis and gait abnormalities. These results indicated that anti-gliomedin IgG may have the potency to pass the blood-nerve barrier in a limited manner.

To circumvent the obstacle of the blood-nerve barrier, anti-gliomedin IgG was passively administrated at disease onset (12 days after immunization) into animals actively immunized against the neuritogenic P2 peptide (EAN-P2). In a previous study, immunization against 200 $\mu \mathrm{g}$ of P2 peptide was found to induce inflammatory demyelination without altering nodal clusters. This study also found that sera from EAN-P2 animals do not react against NF186 or gliomedin. ${ }^{14}$ In this study, I used low doses $(50 \mu \mathrm{g})$ of $\mathrm{P} 2$ peptide to induce a mild neuropathy. As controls, serum IgG was purified from animals sensitized with control $\mathrm{FC}_{\mathrm{C}}$ and was injected into EAN-P2 animals at disease onset. Passive administration of anti-gliomedin IgG exacerbated the severity and duration of EAN-P2 within 2 days (Figure 4). The clinical course of the disease was homogenous between individuals, and the clinical signs reached a peak within 7 days after injection. Then, the clinical symptoms progressively remitted in 4 to 5 weeks (Figure 4, A and B). Recording of $L 6$ ventral spinal roots revealed important conduction deficits in animals administered with antigliomedin IgG (Figure 4C). As early as 24 hours after IgG transfer, CAP amplitude was significantly decreased compared with control animals (Figure 4C and Table 3). Then, the amplitude of the CAPs further decreased concomitantly with the worsening of the clinical deficits. A reduction in conduction velocity became evident at 15 days after immunization (Table 3). At disease peaks (17 to 18 days after immunization), the latency of the initial CAP phase was not significantly delayed (Figure 4C and Table 3); however, three ventral roots of five displayed temporal dispersion (Figure 4C). The recruitment and refractory period also presented a modest, but not significant, displacement (see Supplemental Figure S1B at http://ajp.amjpathol. org). This finding emphasized that antibodies to gliomedin induce important demyelination and conduction loss in motor axons.

\section{Antibodies to Gliomedin Mediate Nodal Alterations}

Histopathologic examination confirmed that IgG transfer induces important demyelination in ventral spinal nerves (Figure $5 \mathrm{H}$ ). Axonal degeneration was only marginally increased after the passive administration of antibodies to gliomedin (Figure 5, E and F), indicating that axonal loss is not responsible for conduction deficits. Semithin tranverse sections further revealed the presence of many infiltrating cell nuclei in L6 spinal nerves at 15 days after immunization (data not shown) and at disease onsets (Figure 5, E and F). Immunostaining for CD3 and ED1 corroborated that anti-gliomedin IgG promoted infiltration of $T$ cells and activated macrophages in spinal nerves at 15 days after immunization and later stages (see Supplemental Figure S3 at http://ajp.amjpathol.org). By contrast, a modest immune cell infiltration was observed in spinal nerves from animals treated for only 24 hours and from control animals (see Supplemental Figure S3 at http:// ajp.amjpathol.org). Immunostaining for rat IgG and C5b-9 revealed an important background staining in L6 ventral spinal nerves, confirming that the blood-nerve barrier is permeabilized in EAN-P2 animals. A total of 24 hours after antibody injection, a strong IgG deposit was detected in $67 \%$ of the nodes in L6 ventral spinal nerves (Figure 5H; see also Supplemental Figure S4 at http:// ajp.amjpathol.org). IgG deposition then rapidly vanished at 15 days after immunization (14\%), and only $11 \%$ of the nodes presented a faint IgG deposition at disease peaks. No overt signs of C5b-9 deposition were found at intact nodes or demyelinated segments in EAN-P2 animals that received anti-gliomedin or control IgG at any stages (data not shown). These data indicated that the immune response followed two steps: a humoral attack against the nodes followed by immune cell infiltration.

To determine whether alterations of Nav channels may be responsible for conduction block in injected animals, the localization of nodal and paranodal components was examined in L6 spinal nerves at different stages of the disease. No signs of demyelination were found in EAN-P2 animals that received control IgG. Accordingly, nodes of Ranvier contained normal-appearing clusters of Nav channels, gliomedin, and NF186 (Figure 5; see also 
Supplemental Table S1 at http://ajp.amjpathol.org). As early as 24 hours after anti-gliomedin IgG injection, important node widening and demyelination were observed (Figure 5, G and $\mathrm{H}$ ). Nevertheless, most nodes contained normal clusters of Nav channels, NF186, and gliomedin at this stage. Only a few demyelinated nodes presented disrupted NF186 or gliomedin aggregates. By 15 days after immunization, the number of nodes showing dis-
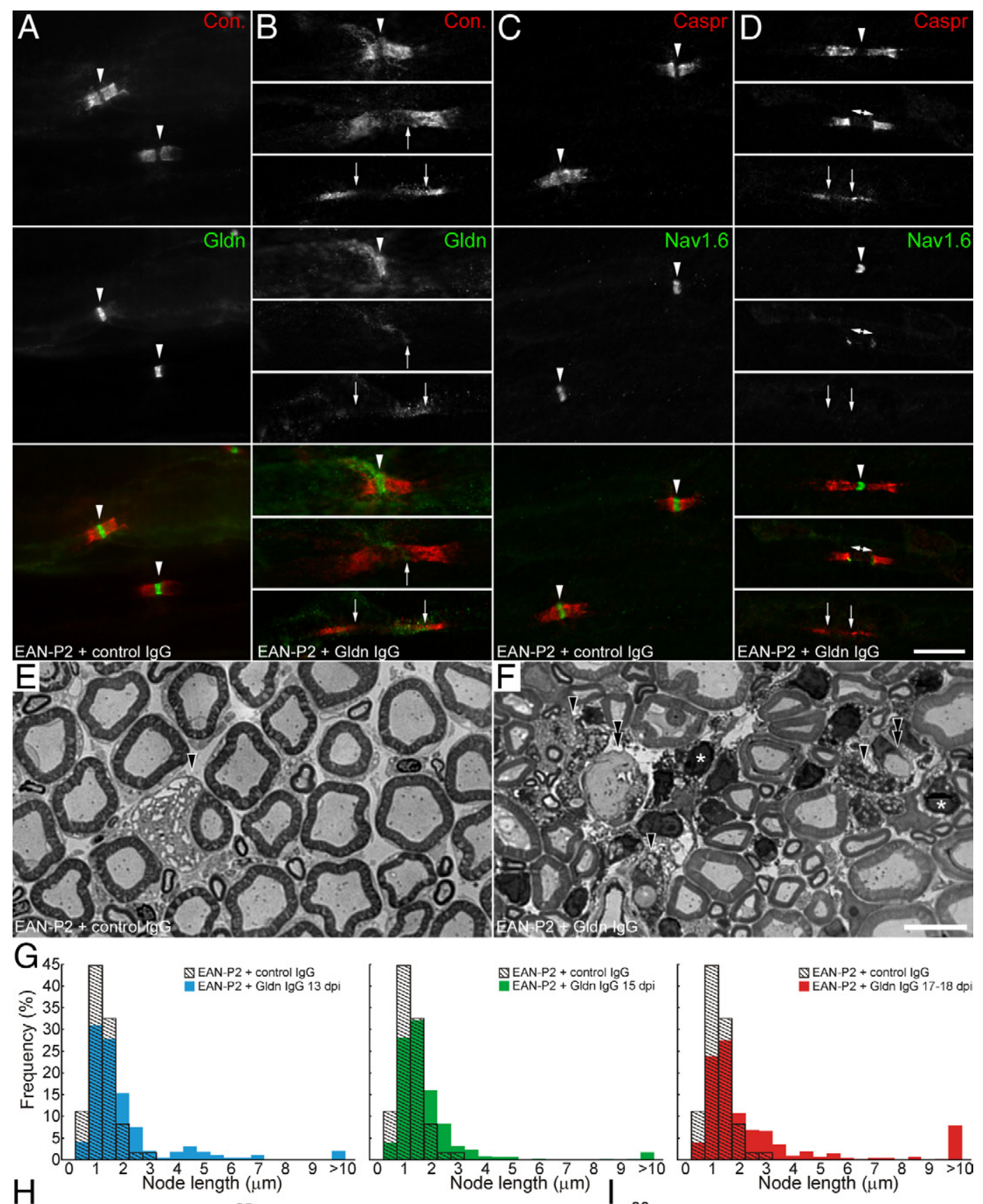

$\mathrm{H}$
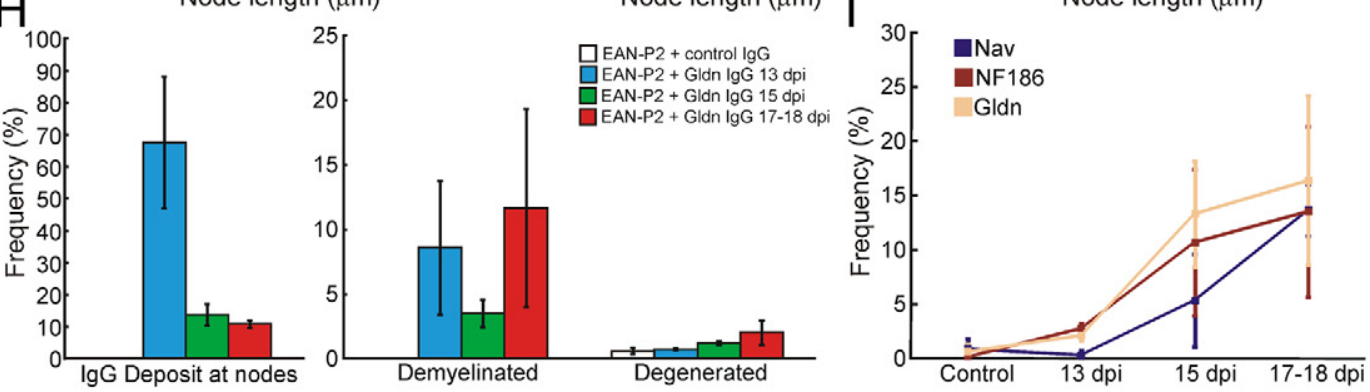
rupted gliomedin or NF186 clusters increased significantly. Concomitantly, alterations in Nav channel aggregates became apparent in demyelinated axons. Interestingly, paranodal demyelination was less prominent than at 13 days after immunization. This finding may correlate with the decreased IgG deposition at nodes. A few days later, nodal cluster disruption increased concomitantly with demyelination. Nav channels, gliomedin, and NF186 were missing or diffusely localized in $>10 \%$ of the nodes (Figure 5; see also Supplemental Table S1 at $h t t p: / / a j p . a m j p a t h o l . o r g)$. At all stages of the disease, disrupted nodal clusters were more commonly associated with elongated or demyelinated segments (Figure $5, \mathrm{~B}$ and $\mathrm{D}$ ). These observations were reminiscent of our previous observations in EAN-PM animals that exhibited autoantibodies against NF186 and gliomedin ${ }^{14}$ and indicated that Nav channel loss is the result of both the disruption of the nodal axoglial contact and demyelination. Altogether, these data indicate that antibodies to gliomedin are pathogenic and affect the axoglial contact at nodes.

\section{Discussion}

Humoral and cellular factors are responsible for the progression of the motor deficits in AIDP and CIDP. According to previous investigations, the binding of antibodies on the outer surface of the Schwann cells may precede myelin damage in AIDP and trigger complement-dependent cytolysis. ${ }^{8-10}$ In severe cases, axonal degeneration also occurs, probably as a consequence of demyelination or inflammation. However, the mechanisms and target antigens underlying demyelination and conduction defects are barely known. Our recent observations highlighted that the node is the locus of the immune attack in GBS. ${ }^{12}$ These observations led to the hypothesis that autoantibodies to nodal CAMs may initiate paranodal demyelination in AIDP and CIDP.

In this study, I demonstrate that immunity directed toward gliomedin, a peripheral CAM, induces paranodal demyelination and peripheral nerve defects in Lewis rats. The passive transfer of anti-gliomedin IgG exacerbated EAN and dismantled the organization of the nodes. Un- like sensitization with P2 peptide or peripheral myelin fraction, ${ }^{28,29}$ immunization against gliomedin did not induce major infiltration of $T$ cells and macrophages. Rather, important deposition of IgG and co-deposition of C5b9 was found at nodes, indicating that complement may be involved in the demyelination process. IgG deposition at nodes was also observed after passive transfer of anti-gliomedin IgG. In these latter animals, the immune response was more complex and followed two steps: IgG deposition at nodes during the early stage of the disease and T-cell and macrophage infiltration in spinal nerves. Demyelination was important when IgG deposition was strong, decreased as IgG deposition vanished, and increased again as immune cell infiltration increased. This finding clearly indicates that both humoral and cellular mechanisms participate in the disease.

What mechanisms may lead to the loss of gliomedin and NF186 and to demyelination? The disappearance of nodal IgG deposits in passively transferred animals suggests that the antigen-lgG complex is rapidly degraded. It is thus plausible that IgG binding onto the Schwann cell surface triggers antigen loss via internalization, destabilization of the gliomedin/NF186/NrCAM complex, or the complement pathway. We did not find clear signs of endocytosis in gliomedin-transfected HEK cells after incubation with autoantibodies to gliomedin from AIDP patients or animals (data not shown). However, we cannot exclude the possibility that antigens may be internalized by Schwann cells or by infiltrating macrophages in vivo. As mentioned previously, complement deposition at nodes was detected in gliomedin-immunized animals. Deposition of complements is also found on intact myelinated fibers in early cases of GBS, whereas high densities of $T$ cells were associated with extensive active demyelination. ${ }^{8,9}$ In EAN, the genetic ablation of $\mathrm{C} 6 \mathrm{com}$ ponent delays the demyelination process but does not affect the extent of myelin damage. ${ }^{30}$ Deposition of IgG and complement at nodes may thus be an early event that participates in Schwann cell vacuolization and myelin retraction. In a rabbit model of acute motor axonal neuropathy, the binding of anti-GM1 IgG and complement at nodes appears to precede node disruption and

\footnotetext{
Figure 5. Anti-gliomedin antibody transfer causes disruption of nodal clusters. A-D: Representative images of L6 ventral roots from EAN-P2 animals injected with control (A and $\mathbf{C}$ ) or anti-gliomedin IgG (B and D) that were stained for contactin (red) and gliomedin (green; $\mathbf{A}$ and $\mathbf{B}$ ) or Nav channels (green; $\mathbf{C}$ and $\mathbf{D})$. EAN-P2 animals injected with control IgG did not exhibit signs of paranodal demyelination or node disruption. Most nodes exhibited normal clusters of Nav channels and gliomedin (arrowheads). Five to six days after passive transfer of anti-gliomedin IgG, clusters of gliomedin and Nav channels were often found disrupted (arrows) particularly in demyelinated axons (B, bottom panel, and $\mathbf{D}$, bottom panel). $\mathbf{E}$ and $\mathbf{F}$ : These are representative micrographs of transverse sections of L6 ventral roots from EAN-P2 animals injected with control (E; 17 days after immunization) or anti-gliomedin IgG (F; 17 days after immunization). Few degenerated axons were found in EAN-P2 animals injected with control or anti-gliomedin IgG. However, a higher number of degenerated (arrowheads) and demyelinated axons (double arrowheads) were found after injection of anti-gliomedin IgG. Note that many infiltrating cells (asterisks) were found after anti-gliomedin IgG administration. G: The distribution of node length was examined in EAN-P2 transferred with control ( $n=4$ animals; 510 axons) or anti-gliomedin antibodies at 13 days after immunization (blue; $n=5$ animals; 391 axons), 15 days after immunization (green; $n=5$ animals; 498 axons), and 17 to 18 days after immunization (red; $n=5$ animals; 524 axons). Node length was significantly increased as early as 24 hours after IgG injection and further increased as the clinical signs worsened $(P<0.01$ by Kolmogorov-Smirnov test). H: The percentage of nodes showing IgG deposition (left panel) and the percentage of demyelinated (middle panel) and degenerated axons (right panel) was measured at 13 days after immunization (blue), 15 days after immunization (green), and at disease peaks (17 to 18 days after immunization; red) in EAN-P2 animals transferred with anti-gliomedin antibodies (five animals for each group). Important IgG deposition was found at nodes 24 hours after the passive transfer. The percentage of demyelinated axons was more important in animals transferred with anti-gliomedin antibodies at disease peaks. Animals transferred with control IgG did not show signs of paranodal demyelination. I: The percentage of nodes with disrupted Nav channel (violet trace), NF186 (maroon trace), and gliomedin clusters (yellow trace) were measured at 13 days after immunization, 15 days after immunization, and at disease peaks (17 to 18 days after immunization) in EAN-P2 animals transferred with control or anti-gliomedin antibodies (five animals for each group). Note that the disruption of NF186 and gliomedin clusters precedes demyelination and Nav channel dispersion. The error bar represents SD. Scale bar $=10 \mu \mathrm{m}$.
} 
axonal loss. ${ }^{31,32}$ The passive transfer of anti-gliomedin IgG did not increase axonal loss, indicating that IgG mediates demyelination after recognition of gliomedin on the Schwann cell surface.

Our results further indicate that infiltrating immune cells participate in the aggravation of EAN and are potentially involved in node alterations. In passively transferred animals, node disruption was accompanied by extensive infiltration of activated macrophages. Also, alterations of axoglial contact at nodes and paranodes correlate with microglial inflammation in patients with multiple sclerosis and in experimental autoimmune encephalomyelitis. ${ }^{33}$ One can easily imagine that macrophages may degrade or inactivate gliomedin by releasing inflammatory factors and proteases or by internalizing the IgG-antigen complex. Gliomedin is incorporated to the extracellular matrix and could be sensitive to protease cleavage. ${ }^{16,17}$ In our previous study, we found that EAN-P2 animals do not show signs of node alterations, despite the presence of demyelination and immune cell infiltration. ${ }^{14}$ Hence, nodal elongation or macrophage invasion are not sufficient to induce the loss of Nav channels. Anti-nodal CAM antibodies might contribute to EAN by favoring the release of inflammatory mediators or the internalization of IgG-ligand immune complexes by macrophages.

Consistent with our previous observations, ${ }^{14}$ we found that Nav channel disruption appeared subsequent to demyelination and to the disappearance of adhesive molecules from nodes in passively transferred animals. The electrophysiologic data further demonstrated that these morphologic alterations underlie important conduction defects in motor axons. Indeed, the passive transfer of anti-gliomedin IgG in EAN-P2 animals resulted in progressive conduction loss and in a significant conduction slowing in the early stage of the disease. At disease onset, the initial phase of the CAPs and the refractory period was not significantly changed. However, some nerves presented temporal dispersion of the CAPs, reflecting important conduction slowing in a subset of axons. Because most demyelinated axons showed a complete loss of Nav channels at this stage, one can easily assume that the regeneration of the action potentials is severely affected and that propagation is blocked in demyelinated segments. These data thus support the idea that demyelination together with the alterations of the axoglial contact result in the diffusion of Nav channels and in progressive conduction loss.

Could autoantibodies to nodal CAMs be critically implicated in the pathology of AIDP or CIDP? We recently found that IgG antibodies directed against gliomedin, neurofascin, or contactin are associated with GBS and CIDP. ${ }^{12}$ The present data indicate that immunity toward gliomedin may orchestrate peripheral nerve inflammation. Gliomedin-sensitized animals displayed fluctuating clinical signs that were reminiscent of CIDP. It is possible that changes in IgG titers or nerve permeability may account for these fluctuations. Because the clinical remission of these animals paralleled the gradual decrease in IgG titers, it is tempting to speculate that autoantibodies to nodal CAMs could participate to GBS or CIDP pathogenesis and notably remission. Consistently, the rapid improvement observed in CIDP and AIDP patients after plasma exchange or intravenous injection of IgG indicates that humoral factors and IgG play a nonnegligible role in the pathogenesis. ${ }^{34-37}$ Future prospect should examine whether the IgG titer correlates with the severity and remission of AIDP and CIDP.

The causes promoting autoimmune reaction in GBS and CIDP patients are, however, enigmatic. More than $50 \%$ of GBS patients develop neuropathic symptoms after an initial infection. ${ }^{38,39}$ Molecular mimicry between lipo-oligosaccharides expressed on the surface of Campylobacter jejuni and human gangliosides appears to trigger antibody response against GM1 and GD1a. ${ }^{40}$ Similarly, we can suspect that molecular mimicry might be responsible for antibody response against nodal CAMs. Secondary immune cascade could also participate in disease worsening by promoting epitope spreading of autoreactive B cells. ${ }^{41}$ Many GBS patients had autoantibodies against multiple nodal CAMs. ${ }^{12,13}$ However, this study found that immunization against gliomedin did not promote secondary reactions toward NF186, despite node deterioration and demyelination. This finding suggests that autoantibodies to nodal CAMs are not simply due to a secondary autoimmune reaction in AIDP and CIDP patients. The reasons why immunization toward NF186 did not generate significant neurologic signs in Lewis rats are unclear. Several previous studies documented that anti-myelin antibodies necessitate T-cell response to pass the blood barrier in the peripheral nervous system and central nervous system. ${ }^{42,43}$ I demonstrate that anti-gliomedin IgG did not lead to a significant neuropathy in absence of blood-nerve barrier breakdown, emphasizing that EAN neuropathy is not solely humorally mediated but also implicating cellular factors that help antibodies gaining access to their targets. It is thus plausible that immunization toward NF186 may not generate a sufficient T-cell response to induce the breakdown of the blood-nerve barrier. The mechanisms influencing autoimmunity toward nodal antigens are thus more complicated and will require further investigation to be fully elucidated.

\section{Acknowledgments}

I thank Dr. Catherine Faivre-Sarrailh for thoughtful comments and Drs. Laurence Goutebroze, Alex Gow, Elior Peles, and Vann Bennett for the generous gift of antibodies and constructs.

\section{References}

1. Hughes RA, Cornblath DR: Guillain-Barré syndrome. Lancet 2005 , 366:1653-1666

2. Prineas JW: Pathology of the Guillain-Barré syndrome. Ann Neurol 1981, 9:6-19

3. Feasby TE, Brown WF, Gilbert JJ, Hahn AF: The pathological basis of conduction block in human neuropathies. J Neurol Neurosurg Psychiatry 1985, 48:239-244

4. Brechenmacher C, Vital C, Deminiere C, Laurentjoye L, Castaing Y, Gbikpi-Benissan G, Cardinaud JP, Favarel-Garrigues JP: GuillainBarré syndrome: an ultrastructural study of peripheral nerve in 65 patients. Clin Neuropathol 1987, 6:19-24 
5. Hughes R, Atkinson P, Coates P, Hall S, Leibowitz S: Sural nerve biopsies in Guillain-Barré syndrome: axonal degeneration and macrophage-associated demyelination and absence of cytomegalovirus genome. Muscle Nerve 1992, 15:568-575

6. Kanda T, Hayashi H, Tanabe H, Tsubaki T, Oda M: A fulminant case of Guillain-Barré syndrome: topographic and fibre size related analysis of demyelinating changes. J Neurol Neurosurg Psychiatry 1989 52:857-864

7. Fuller GN, Jacobs JM, Lewis PD, Lane RJ: Pseudoaxonal GuillainBarré syndrome: severe demyelination mimicking axonopathy: a case with pupillary involvement J Neurol Neurosurg Psychiatry 1992, 55 1079-1083

8. Hafer-Macko CE, Sheikh KA, Li CY, Ho TW, Cornblath DR, McKhann GM, Asbury AK, Griffin JW: Immune attack on the Schwann cell surface in acute inflammatory demyelinating polyneuropathy. Ann Neurol 1996, 39:627-637

9. Wanschitz J, Maier H, Lassmann H, Budka H, Berger T: Distinct time pattern of complement activation and cytotoxic $\mathrm{T}$ cell response in Guillain-Barré syndrome. Brain 2003, 126:2034-2042

10. Lu JL, Sheikh KA, Wu HS, Zhang J, Jiang ZF, Cornblath DR, McKhann GM, Asbury AK, Griffin JW, Ho TW: Physiologic-pathologic correlation in Guillain-Barré syndrome in children. Neurology 2000, 54:33-39

11. Stoll G, Schmidt B, Jander S, Toyka KV, Hartung HP: Presence of the terminal complement complex (C5b-9) precedes myelin degradation in immune-mediated demyelination of the rat peripheral nervous system. Ann Neurol 1991, 30:147-155

12. Devaux JJ, Odaka M, Yuki N: Nodal proteins are target antigens in Guillain-Barré syndrome. J Peripher Nerv Syst 2012, 17:62-71

13. Pruss H, Schwab JM, Derst C, Gortzen A, Veh RW: Neurofascin as target of autoantibodies in Guillain-Barré syndrome. Brain 2011, 134 : 173

14. Lonigro A, Devaux JJ: Disruption of neurofascin and gliomedin at nodes of Ranvier precedes demyelination in experimental allergic neuritis. Brain 2009, 132:260-273

15. Susuki K, Rasband MN: Molecular mechanisms of node of Ranvier formation. Curr Opin Cell Biol 2008, 20:616-623

16. Eshed Y, Feinberg K, Carey DJ, Peles E: Secreted gliomedin is a perinodal matrix component of peripheral nerves. J Cell Biol 2007 , 177:551-562

17. Maertens B, Hopkins D, Franzke CW, Keene DR, Bruckner-Tuderman L, Greenspan DS, Koch M: Cleavage and oligomerization of gliomedin, a transmembrane collagen required for node of Ranvier formation. J Biol Chem 2007, 282:10647-10659

18. Davis JQ, Lambert S, Bennett V: Molecular composition of the node of Ranvier: identification of ankyrin-binding cell adhesion molecules neurofascin (mucin + third FNIII domain-) and NrCAM at nodal axon segments. J Cell Biol 1996, 135:1355-1367

19. Feinberg K, Eshed-Eisenbach Y, Frechter S, Amor V, Salomon D, Sabanay H, Dupree JL, Grumet M, Brophy PJ, Shrager P, Peles E: A glial signal consisting of gliomedin and NrCAM clusters axonal $\mathrm{Na}+$ channels during the formation of nodes of Ranvier. Neuron 2010, 65:490-502

20. Labasque M, Devaux JJ, Leveque C, Faivre-Sarrailh C: Fibronectin type III-like domains of neurofascin-186 protein mediate gliomedin binding and its clustering at the developing nodes of Ranvier. J Biol Chem 2011, 286:42426-42434

21. Sherman DL, Tait S, Melrose S, Johnson R, Zonta B, Court FA, Macklin WB, Meek S, Smith AJ, Cottrell DF, Brophy PJ: Neurofascins are required to establish axonal domains for saltatory conduction. Neuron 2005, 48:737-742

22. Charles P, Tait S, Faivre-Sarrailh C, Barbin G, Gunn-Moore F, Denisenko-Nehrbass N, Guennoc AM, Girault JA, Brophy PJ, Lubetzki C: Neurofascin is a glial receptor for the paranodin/Casprcontactin axonal complex at the axoglial junction. Curr Biol 2002 , 12:217-220

23. Zonta B, Tait S, Melrose S, Anderson H, Harroch S, Higginson J, Sherman DL, Brophy PJ: Glial and neuronal isoforms of Neurofascin have distinct roles in the assembly of nodes of Ranvier in the central nervous system. J Cell Biol 2008, 181:1169-1177

24. Eshed Y, Feinberg K, Poliak S, Sabanay H, Sarig-Nadir O, Spiegel I, Bermingham JR, Peles E: Gliomedin mediates Schwann cell-axon interaction and the molecular assembly of the nodes of Ranvier. Neuron 2005, 47:215-229
25. Uyemura K, Suzuki M, Kitamura K, Horie K, Ogawa Y, Matsuyama H, Nozaki S, Muramatsu I: Neuritogenic determinant of bovine P2 protein in peripheral nerve myelin. J Neurochem 1982, 39:895-898

26. Southwood C, He C, Garbern J, Kamholz J, Arroyo E, Gow A: CNS myelin paranodes require Nkx6-2 homeoprotein transcriptional activity for normal structure. J Neurosci 2004, 24:11215-11225

27. Menegoz M, Gaspar P, Le Bert M, Galvez T, Burgaya F, Palfrey C Ezan P, Arnos F, Girault JA: Paranodin, a glycoprotein of neuronal paranodal membranes. Neuron 1997, 19:319-331

28. Hahn AF, Feasby TE, Steele A, Lovgren DS, Berry J: Demyelination and axonal degeneration in Lewis rat experimental allergic neuritis depend on the myelin dosage. Lab Invest 1988, 59:115-125

29. Hahn AF, Feasby TE, Wilkie L, Lovgren D: $P_{2}$-peptide induced experimental allergic neuritis - a model to study axonal degeneration. Acta Neuropathol 1991, 82:60-65

30. Tran GT, Hodgkinson SJ, Carter NM, Killingsworth M, Nomura M, Verma ND, Plain KM, Boyd R, Hall BM: Membrane attack complex of complement is not essential for immune mediated demyelination in experimental autoimmune neuritis. J Neuroimmunol 2010, 229:98-106

31. Susuki K, Rasband MN, Tohyama K, Koibuchi K, Okamoto S, Funakoshi K, Hirata K, Baba H, Yuki N: Anti-GM1 antibodies cause complement-mediated disruption of sodium channel clusters in peripheral motor nerve fibers. J Neurosci 2007, 27:3956-3967

32. Susuki K, Yuki N, Schafer DP, Hirata K, Zhang G, Funakoshi K, Rasband MN: Dysfunction of nodes of Ranvier: a mechanism for anti-ganglioside antibody-mediated neuropathies. Exp Neurol 2012 233:534-542

33. Howell OW, Rundle JL, Garg A, Komada M, Brophy PJ, Reynolds R: Activated microglia mediate axoglial disruption that contributes to axonal injury in multiple sclerosis. J Neuropathol Exp Neurol 2010, 69:1017-1033

34. Diener HC, Haupt WF, Kloss TM, Rosenow F, Philipp T, Koeppen S, Vietorisz A: A preliminary, randomized, multicenter study comparing intravenous immunoglobulin, plasma exchange, and immune adsorption in Guillain-Barré syndrome. Eur Neurol 2001, 46:107-109

35. McKhann GM, Griffin JW, Cornblath DR, Quaskey SA, Mellits ED: Role of therapeutic plasmapheresis in the acute Guillain-Barré syndrome. J Neuroimmunol 1988, 20:297-300

36. Hughes RA, Donofrio P, Bril V, Dalakas MC, Deng C, Hanna K, Hartung HP, Latov N, Merkies IS, van Doorn PA: Intravenous immune globulin ( $10 \%$ caprylate-chromatography purified) for the treatment of chronic inflammatory demyelinating polyradiculoneuropathy (ICE study): a randomised placebo-controlled trial. Lancet Neurol 2008 , 7:136-144

37. Mendell JR, Barohn RJ, Freimer ML, Kissel JT, King W, Nagaraja HN Rice R, Campbell WW, Donofrio PD, Jackson CE, Lewis RA, Shy M, Simpson DM, Parry GJ, Rivner MH, Thornton CA, Bromberg MB, Tandan R, Harati Y, Giuliani MJ: Randomized controlled trial of IVIg in untreated chronic inflammatory demyelinating polyradiculoneuropathy. Neurology 2001, 56:445-449

38. Hughes RA, Hadden RD, Gregson NA, Smith KJ: Pathogenesis of Guillain-Barré syndrome. J Neuroimmunol 1999, 100:74-97

39. van Doorn PA, Ruts L, Jacobs BC: Clinical features, pathogenesis, and treatment of Guillain-Barré syndrome. Lancet Neurol 2008, 7:939-950

40. Yuki N, Susuki K, Koga M, Nishimoto Y, Odaka M, Hirata K, Taguchi K, Miyatake T, Furukawa K, Kobata T, Yamada M: Carbohydrate mimicry between human ganglioside GM1 and Campylobacter jejuni lipooligosaccharide causes Guillain-Barré syndrome. Proc Natl Acad Sci U S A 2004, 101:11404-11409

41. Robinson WH, Fontoura P, Lee BJ, de Vegvar HE, Tom J, Pedotti R, DiGennaro CD, Mitchell DJ, Fong D, Ho PP, Ruiz PJ, Maverakis E, Stevens DB, Bernard CC, Martin R, Kuchroo VK, van Noort JM, Genain CP, Amor S, Olsson T, Utz PJ, Garren H, Steinman L: Protein microarrays guide tolerizing DNA vaccine treatment of autoimmune encephalomyelitis. Nature Biotechnol 2003, 21:1033-1039

42. Spies JM, Pollard JD, Bonner JG, Westland KW, McLeod JG: Synergy between antibody and P2-reactive $T$ cells in experimental allergic neuritis. J Neuroimmunol 1995, 57:77-84

43. Linington $\mathrm{C}$, Bradl M, Lassman $\mathrm{H}$, Brunner C, Vass K: Augmentation of demyelination in rat acute allergic encephalomyelitis by circulating mouse monoclonal antibodies directed against a myelin/oligodendrocyte glycoprotein. Am J Pathol 1988, 130:443-454 